Respiration 2013;85:85-86

DOI: $10.1159 / 000343427$

\section{Talc Instillation Consensus Aids Differentiating Successful from Unsuccessful Pleurodesis: A Survey on the Interpretation of Pleural Approximation after Chest Tube Placement}

\section{R.C. Boshuizen ${ }^{\mathrm{a}}$, A.D. Vincent ${ }^{\mathrm{b}}$, P.W.A. Kunst ${ }^{\mathrm{a}}$, J.A. Burgers ${ }^{\mathrm{a}}$,} M.M. van den Heuvel ${ }^{\text {a }}$

Departments of a Thoracic Oncology and ${ }^{\mathrm{b}}$ Biometrics, The Netherlands Cancer Institute - Antoni van Leeuwenhoek Hospital, Amsterdam, The Netherlands

Key Words

Pleurodesis • Malignant pleural effusion - Lung expansion • Chest X-ray $\cdot$ Talc slurry
Pleural approximation is the most important predictor for successful pleurodesis [1]. We performed an online survey to investigate variation in pulmonologists' opinions regarding: (1) lung expansion, (2) talc instillation, and (3) the expected success rate of pleurodesis after conventional pleural fluid drainage. Chest Xrays of patients suffering from malignant pleural effusion $(n=50)$, made after full drainage and used to decide whether or not to instill talc, were reviewed by experienced pulmonologists. All patients had been treated prior to this questionnaire. Thirty out of 100 hospitals responded. When pulmonologists reported that the lung was expanded, they recommended pleurodesis in $89 \%$ of the cases. When they reported the lung not to be expanded, they still advised pleurodesis in $38 \%$ of cases. Pulmonologists disagreed more frequently on lung expansion than they did on recommending pleurodesis (fig. 1a, b). Agreement was not related to either patient (gender, age or tumor type) or pulmonologist characteristics (age, gender, personal experience or ultrasound usage).

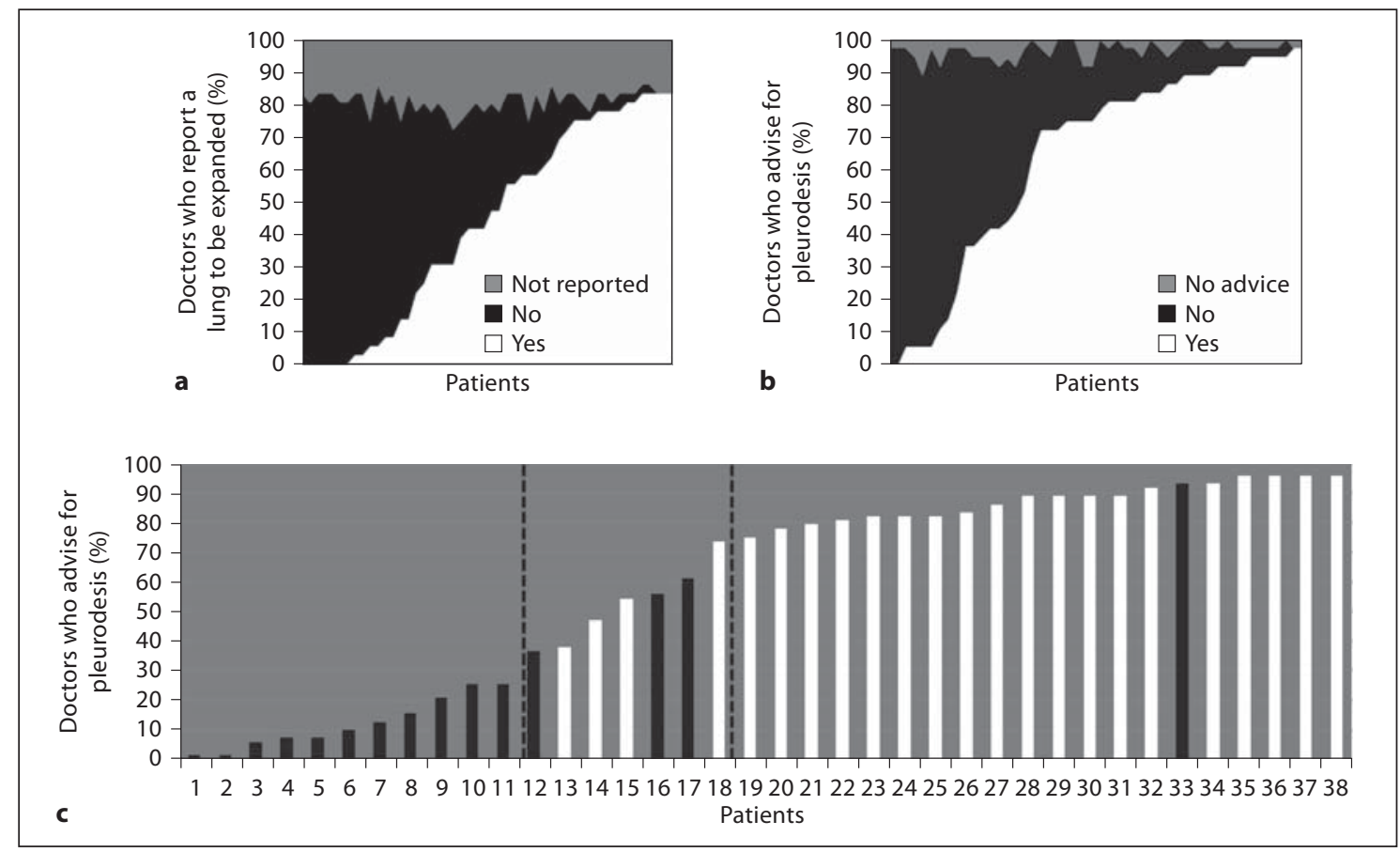

Fig. 1. Survey on interpretation of lung expansion in patients with malignant pleural effusion after complete pleural fluid evacuation. a 'Do you report this lung to be expanded?' Percentage of pulmonologists who report a lung to be expanded (white area). b 'Would you perform pleurodesis?' More often agreement was reached (i.e. either yes or no was answered by at least $75 \%$ of the pulmonologists). More positive answers (white area) were given for pleurodesis advice. c Advice for pleurodesis compared with the real outcome. Thirty-eight pleurodeses were performed; of these, 23 were considered to be successful (white bars) and 15 were considered to be failures (black bars). In 31 patients consensus (i.e. less than $25 \%$ or greater than $75 \%$ of doctors recommending pleurodesis) about treatment was reached to either instill talc or remove the drain. There was no agreement for treatment of $7 \mathrm{pa}-$ tients (between dotted lines).

\section{KARGER}

Fax +41613061234 E-Mail karger@karger.ch www.karger.com
(C) 2012 S. Karger AG, Basel

0025-7931/13/0851-0085\$38.00/0

Accessible online at: www.karger.com/res
R.C. Boshuizen, MD

Department of Thoracic Oncology

The Netherlands Cancer Institute - Antoni van Leeuwenhoek Hospital

Plesmanlaan 121, NL-1066 CX Amsterdam (The Netherlands)

E-Mail r.boshuizen@nki.nl 
In this patient cohort, which was previously reported as part of a prospective trial on pleurodesis efficacy, talc slurry had been instilled in approximately 75\% (38 patients) [2]. Sixty-one percent of these patients (intention to treat analysis: $46 \%$ ) had a successful pleurodesis (as defined by the absence of fluid recurrence, or reintervention, and survival for $>2$ months after talc instillation). In 7 out of 38 patients, talc was instilled despite the fact that in this online survey no consensus was reached between pulmonologists about whether to treat these patients or not (i.e. less than $75 \%$ agreement). However, in 4 of these patients (57\%) the pleurodesis was successful (fig. 1c), and this equals the overall success rate. When 2 pulmonologists independently gave the same assessment, the ability to accurately predict the success of pleurodesis increased from 75 to $81 \%$ ( $p<0.0001)$.

Thus, the most reliable predictor for the outcome of pleurodesis is prone to heterogeneous interpretation. Our results suggest that talc pleurodesis may be successful in cases of incomplete lung expansion.

\section{Acknowledgement}

We thank the Dutch Society of Pulmonologists (NVALT) and M. Groot Obbink for their help with distributing the questionnaires.

\section{Financial Disclosure and Conflicts of Interest}

None of the authors reports any conflicts of interest.

\section{References}

1 Lan RS, Lo SK, Chuang ML, et al: Elastance of the pleural space: a predictor for the outcome of pleurodesis in patients with malignant pleural effusion. Ann Intern Med 1997;126:768-774

2 Burgers JA, Kunst PW, Koolen MG, et al: Pleural drainage and pleurodesis: implementation of guidelines in four hospitals. Eur Respir J 2008; 32:1321-1327. 